\title{
INGESTED FORK IMPACTED IN STOMACH - CHALLENGE FOR RISKY ENDOSCOPY OR PRIMARY SURGERY
}

\author{
Kirien Kjossev, Ventsislav Mutafchiyski, Ivan Teodosiev, Georgi Popivanov \\ Military Medical Academy, Sofia
}

\begin{abstract}
The ingestion of metallic (radiopaque) foreign bodies remains a common problem amongst prison population. A 34-year-old male prisoner swallowed a dinner fork in an attempt to escape justice. Attempts for endoscopic extraction were unsuccessful. The patient underwent laparotomy and via gastrotomy a $15-\mathrm{cm}$ length fork was removed. Based upon our previous experience, we recommend immediate surgical removal if the attempt for endoscopic retrieval had failed. Prevention measures in prison inmates may significantly decrease the incidence rate.
\end{abstract}

Keywords: foreign body, removal, surgery, ingested fork, prisoners

The accidentally ingestion of foreign bodies occurs in the psychiatric and pediatric group, but voluntary ingestion of normally inedible materials seems confined to specific high-risk groups of adultprison inmates. Through ingestion of foreign bodies, such as spoons or knives, prisoners hope to score a trip to the hospital and a brief respite from prison life (1).

We present a case ofa 34-year-old male prisoner who was admitted with upper abdominal pain. Initially he was willing to state only that he swallowed a dinner fork two days earlier in an attempt to escape justice. Abdominal radiograph showed a metallic foreign object in the gastric region (Figure 1). Attempts for endoscopic extraction using retrieval forceps and snare were unsuccessful because of the fork's position (prongs up). The patient underwent

Address for correspondence:

Kirien Kjossev

Military Medical Academy

Department of Abdominal Surgery

3 Georgi Sofijski Blvd

1606 Sofia

e-mail:kirien@abv.bg

Received: December 27, 2014

Accepted: March 11, 2015

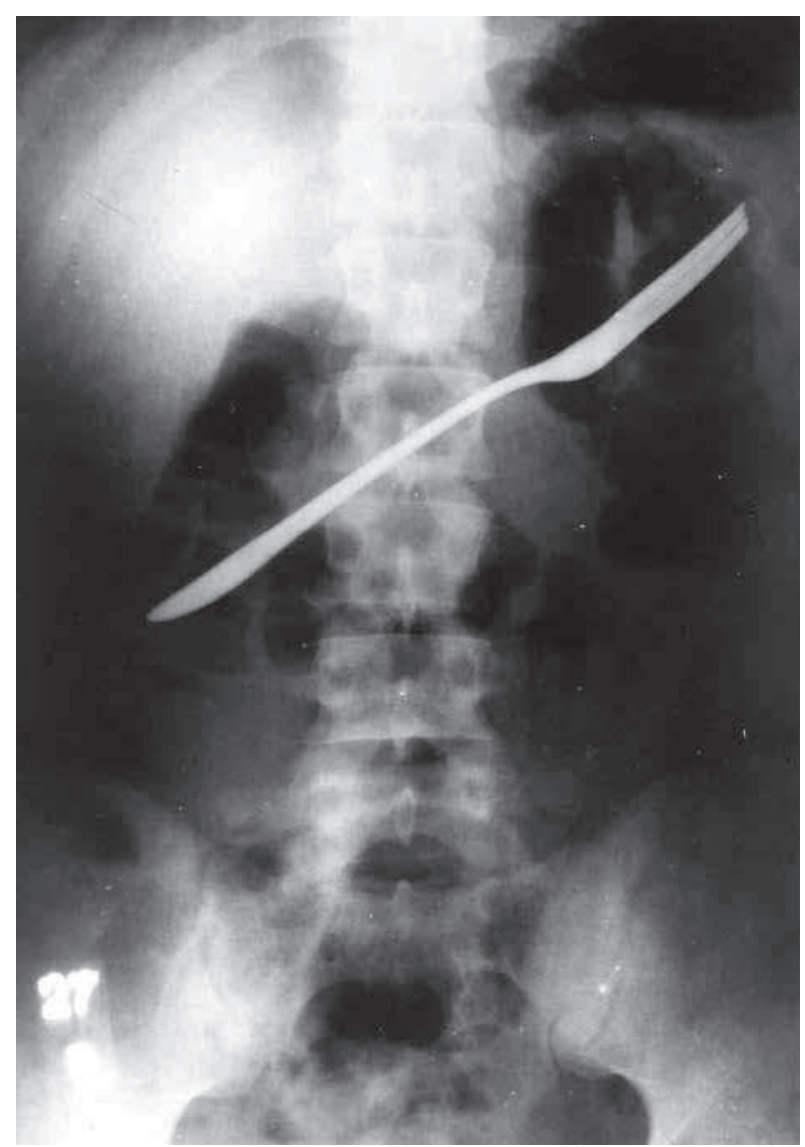

Fig. 1. Plain radiography showing ingested $15-\mathrm{cm}$ length fork in stomach. 
Ingested fork impacted in stomach - challenge for risky endoscopy or primary surgery

laparotomy and via gastrotomy a $15-\mathrm{cm}$ length fork was removed. The patient recovered promptly and was discharged on $5^{\text {th }}$ postoperative day.

Management of foreign body impaction in the stomach is controversial. Most foreign bodies pass spontaneously through the gastrointestinal tract with no need of any interventions. Long objects in the range of 6-10 cm in length, such as spoons, forks, knives and toothbrushes, are less likely to pass the duodenal curve and often require active intervention to remove them from the stomach.Moreover,objects greater than $2 \mathrm{~cm}$ in diameter may not pass through the pylorus (2).

Various available options for treatment include endoscopic, surgical, laparoscopic, and laparo-endoscopic approach. Endoscopic removal is needed in $10 \%$ to $20 \%$ of the cases and in about $1 \%$ of the cases, surgical intervention is required, depending on the nature, shape, size, number and location of the foreign bodies (3).

Many studies have shown successful early endoscopic foreign body removal, thus avoiding the high morbidity associated with obstruction and perforation of the stomach (4). Despite the $6 \%$ complication rate for endoscopic extraction and often failure of the procedure, this method of treatment is considered the safest (5). The complication rate increases in case of a sharp and impacted foreign body.

Long objects are a matter of specific challenge due to difficulties in attempts to orient the object parallel to the esophagus in a secure position in order to facilitate extraction through the lower esophageal sphincter. Endoscopic removal of foreign objects should be performed by an experienced endoscopist using accessories such as snares, Dormia baskets or strong-toothed graspers. Several techniques have described the removal through the use of double snare method, two simultaneous endoscopes, baloontiped scopes, and side-viewing endoscope and one snare (4). The dimensions of the ingested fork in the present case were $15 \mathrm{~cm}$ in length and $3 \mathrm{~cm}$ in diameter and the attempts for orienting in secure position were unsuccessful. Multiple erosions and hemorrhage spots over the mucosa of the fundus and the body appeared during endoscopy. Therefore, gastrotomy and removal of the foreign body was performed.
In case of failure of endoscopic retrieval, rapid surgical extraction of long gastric foreign bodies is judicious. Laparoscopic approach has to be considered at first line when decision for surgery is done (5). This method offers faster recovery and generally is less invasive and less painful. Strong indications for surgery exist when signs of complications such as perforation, obstruction or hemorrhage occur or appear imminent in view of the shape and size of the objects $(2,3)$. Gastric foreign bodies are usually removed by longitudinal gastrotomy. If complications occur, a small percentage of cases can be treated by gastric resections.

Available literature data concerning foreign body ingestion reveals a major difference within the prison population where surgical or endoscopic intervention was required in $36 \%$ of these patients, in contrast to $1 \%$ in the general population (1). Many prisoners who deliberately swallow foreign bodies ingest multiple objects or repeat the ingestion in a further episode. Based upon our previous experience with five patients in whom multiple ingestions of "gastrointestinal crosses" inevitably led to perforations of the stomach, duodenum, and small intestine in each instance, we recommend immediate surgical removal if the attempt for endoscopic retrieval had failed.

In conclusion, it has to be noted that for the most commonly presented group of patients with deliberately and consciously ingested foreign bodies (prison inmates), prevention measures which may significantly decrease the incidence rate should be proposed. Such measures include improvement of the prison environment and use of behavioral modification and refraining from such incidents.This may be the best approach for treatment.

\section{REFERENCES}

1. Bisharat M, O'Donnell ME, Gibson N, Mitchell M, Refsum SR, Carey PD, Spence RAJ, Lee J. Foreign body ingestion in prisoners - The Belfast experience. Ulster Med J, 2008;77:110-114.

2. Velitchkov NG, Grigorov GI, Losanoff JE, Kjossev $\mathrm{KT}$. Ingested foreign bodies of the gastrointestinal tract: retrospective analysis of 542 cases. World J Surg, 1996;20:1001-1005.

3. Eisen GM, Baron TH, Dominitz JA et al. American Society for Gastrointestinal Endoscopy. .Guide- 
line for the management of ingested foreign bodies.

Gastrointest Endosc, 2002; 55:802-806.

4. El Hajj, Clarke BW, Slivka A. Retrieval of a long foreign body from the stomach with a duodenoscope. Endoscopy, 2011;43:E107-E108.

5. Kurzbauma A, Nicolab A, Liebermana L, Saforia G. Laparoscopic removal of a swallowed dinner fork from the stomach: a minimally-invasive management for swallowed gastrointestinal foreign bodies. Israeli J Emerg Med, 2006; 6:33-35. 